\title{
Light induced apoptosis is accelerated in transgenic retina overexpressing human EAT/mcl-1, an anti-apoptotic bcl-2 related gene
}

Kei Shinoda, Yu Nakamura, Kenichi Matsushita, Kouji Shimoda, Hajime Okita, Mariko Fukuma, Taketo Yamada, Hisao Ohde, Yoshihisa Oguchi, Jun-ichi Hata, Akihiro Umezawa

\begin{abstract}
Backgroundlaim-EAT/mcl-1 (EAT), an immediate early gene, functions in a similar way to bcl-2 in neutralising Bax mediated cytotoxicity, suggesting that EAT is a blocker of cell death. The aim of this study was to determine the effect of overexpression of the human EAT gene on light induced retinal cell apoptosis.

Methods-EAT transgenic mice incorporating the EF-1 $\alpha$ promoter were utilised, and expression of human EAT was detected by RT-PCR. Light damage was induced by raising mice under constant illumination. Two groups of animals, EAT transgenic mice $(n=14)$ and littermates $(\mathbf{n}=13)$, were examined by ERG testing and histopathology at regular time points up to 20 weeks of constant light stimulation. Electrophysiological and histopathological findings were evaluated by established systems of arbitrary scoring as
\end{abstract} scores $0-2$ and scores $0-3$, respectively.

Department of
Ophthalmology, Keio University School of Medicine, 35

Shinanomachi,

Shinjuku-ku, Tokyo

160-8582, Japan

K Shinoda

Y Nakamura

H Ohde

Y Oguchi

Department of

Pathology

K Matsushita

H Okita

M Fukuma

T Yamada

J-i Hata

A Umezawa

Department of Internal Medicine

K Matsushita

Laboratory Animal

Center

K Shimoda

Correspondence to: Akihiro Umezawa,

Department of Pathology,

Keio University School of

Medicine, Shinanomachi,

Shinjuku-ku, Tokyo,

160-8582, Japan

umezawa@

1985.jukuin.keio.ac.jp

Accepted for publication

5 April 2001 response was significantly lower in EAT transgenic mice $(0.79(0.89))$ than in littermates $(1.69 \quad(0.48)) \quad(p<0.01)$. Although the differences between the two survival curves did not reach statistical significance $(p=0.1156)$, the estimated incidence of electrophysiological retinal damage was higher in EAT mice $(0.0495 /$ mouse/week; $95 \%$ confidence interval (CI) $0.0347-0.0500$ ) than in littermates (0. 0199/mouse/week; 95\% CI 0.0035-0.0364). The mean scores (SD) for histopathological retinal degeneration were $2.31(0.63)$ in littermates and 1.43 (1.22) in EAT transgenic mice $(p=0.065)$. However, Kaplan-Meier curves for histopathological failure in two groups of mice showed that retinal photoreceptor cells were preserved significantly against constant light in the littermate compared with transgenic mice $(p=0.0241)$. The estimated incidence of histopathological retinal damage was $0.0042 / \mathrm{mouse} /$ week in the littermates (95\% CI 0-0.0120) and 0.0419 / mouse/week in the EAT mice $(95 \%$ CI 0.0286-0.0500).

Conclusion-Retinal photoreceptor cell apoptosis under constant light stimulation is likely to be accelerated in transgenic retina overexpressing EAT.

(Br f Ophthalmol 2001;85:1237-1243)
Results-The mean score (SD) of ERG
The EAT/mcl-1 (EAT) gene was identified by differential screening of cDNA libraries derived from a human myeloid leukaemia cell line induced to undergo differentiation in culture. ${ }^{1}$ Expression of EAT is transiently induced in these leukaemia cells after stimulation with agents that promote terminal differentiation, suggesting that this gene functions as an immediate early gene. The EAT gene is a member of the bcl-2 gene family, because it contains the bcl-2 homology domains 1, 2, 3, and $4 .^{2-5}$ bcl- 2 related genes have either positive or negative regulatory effects on apoptosis in vitro and in vivo. ${ }^{6-8}$ Previous studies have established that Bcl-2, Bcl-xL, Bcl-w, Bfl-1, EAT, and A1 are anti-apoptotic molecules while Bax, Bak, Bcl-xS, Bad, Bid, Bik, and Hrk are pro-apoptotic molecules. ${ }^{9-19}$ The rapid increase in expression of EAT produced by differentiating or cytotoxic agents was found to involve an increase in EAT transcription, ${ }^{20-22}$ indicating that the EAT early induction gene is similar to the serum stimulated early response genes. ${ }^{23-28}$ The EAT protein also exhibits rapid turnover (half life of 1-3 hours) ${ }^{29}$ because, unlike other bcl-2 family members, the $\mathrm{N}$-terminal region contains two PEST sequences (enriched in proline, glutamic acid, serine, and threonine). The intracellular distribution of EAT appears to be more widespread than Bcl-2. ${ }^{30} 31$

The in vivo effects of bcl-2 related genes have been investigated in transgenic or knockout mice. bcl-2 transgenic mice increased cell survival of $B$ cells, $T$ cells, and thymocytes. ${ }^{32-35}$ Mice deficient for bcl-2 display increased apoptosis in selected tissues. ${ }^{36}$ These phenotypes confirm the anti-apoptotic functions established for bcl-2 in vitro. In contrast, bax transgenic mice have increased apoptosis of $\mathrm{T}$ cells, whereas mice deficient for bax demonstrate hyperplasia of thymocytes and B cells. ${ }^{37-39}$ Male Bax deficient mice are infertile with atrophic adult testes and an empty epididymis and vas deferens; a complete cessation of mature sperm cell production occurs in these mice. ${ }^{39}$ These phenotypes result from the pro-apoptotic functions of Bax.

Apoptosis is the main mechanism of cell loss in induced ${ }^{4041}$ or inherited retinal degeneration $^{42}{ }^{43}$ in animal models, and it may represent the mechanism of cell death in many human retinal diseases. The pathogenesis of retinal degeneration is largely unexplained, and there are no current therapies. Excessive light may enhance the progression and severity of human 
A

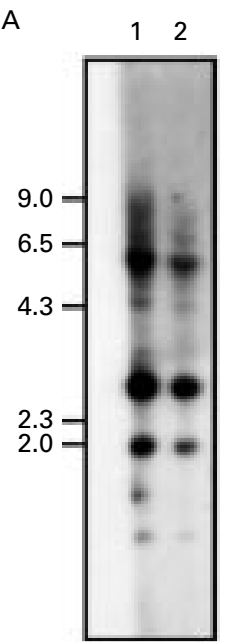

B

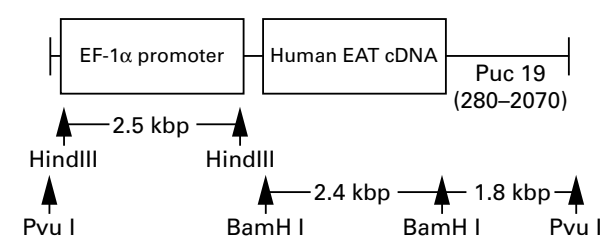

C

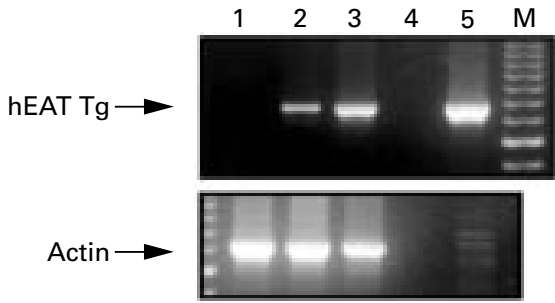

Figure 1 Expression of the human EAT transgene. (A) Southern blot analysis of tail DNA from heterozygote transgenic lines. EcoRI digested tail genomic DNA was hybridised with a ${ }^{32} \mathrm{P}$ labelled EF1a-EAT probe. Kilobase size markers are shown on the left.

Orientation of the human EAT transgene was determined to be head to tail in all lines. The copy numbers of the transgene per diploid genome for each line are: 150 (E3), and 20

(E12), as shown in lanes 1 and 2, respectively. To determine the copy number of the transgene, transgene fragment copy numbers were also hybridised. (B) Schema of the EF1a human EAT (EF1a-EAT) transgene construct. The PvuI fragment was used as the transgene. The same $6.7 \mathrm{~kb}$ PvuI fragment was used as a probe for Southern blot hybridisation. This human EAT transgene, driven by the EF-1a promoter, was injected into the fertilised eggs. (C) Expression of the human EAT transgene as assayed in isolated retinas from the transgenic lines. RT-PCR was performed with a primer set which detected only the human EAT gene without detecting the endogenous murine EAT gene lane 1: non-transgenic mice; lane 2: E12; lane 3: E13; lane 4: no RNA; lane 5: plasmid containing the human EAT gene). Retinas from a non-transgenic mouse and the human EAT DNA served as negative and positive controls, respectively. $A 100$ bp ladder is shown as a size marker in lane M. $\beta$ actin (729 bp) RT-PCR products are shown to demonstrate the integrity of the isolated RNA (lower section).

age related macular degeneration and some forms of retinitis pigmentosa. ${ }^{44-46}$ Animal models of light induced retinal degeneration correlate well with the pathology observed in human donor retinas affected with retinitis pigmentosa. ${ }^{47}$ In addition, apoptosis in photoreceptor (PR) cells has been seen in early stages of human retinitis pigmentosa. ${ }^{49}$ Likewise, several animal models with inherited retinal degeneration show an increased susceptibility to light damage compared with control animals. ${ }^{50}$ Exposure to excessive levels of white light induces PR apoptosis, thus providing an excellent model to analyse degenerative PR loss. ${ }^{51}$

PRs overexpressing bcl-2 have been shown to survive light induced insults longer than PRs with normal endogenous levels of bcl-2. ${ }^{52}$ Expression of bcl-2 protects against PR degeneration in retinal degeneration slow (rds) mice. $^{53} 54$ Increased expression of bcl-2 and bcl-xL may be a necessary component in a strategy to inhibit PR cell death. These findings led us to examine the effect of overexpression of the human EAT gene on light induced retinal cell apoptosis.

\section{Materials and methods}

MICE TRANSGENIC FOR HUMAN EAT GENE

To generate transgenic mice that express human EAT, a transgene was constructed with the human EF-1 $\alpha$ promoter linked to human EAT $(\mathrm{EF} 1 \alpha-\mathrm{EAT})^{55}$ (Fig 1). A DNA solution $(3 \mu \mathrm{g} / \mathrm{ml})$ was microinjected into the male pronuclei of fertilised mouse eggs taken from superovulated $\mathrm{B} 6 \mathrm{C} 3 \mathrm{~F} 1(\mathrm{C} 57 \mathrm{BL} / 6 \times \mathrm{C} 3 \mathrm{H} / \mathrm{He})$

females. The injected eggs were surgically transferred to the oviducts of B6C $3 F 1$ pseudopregnant female mice. Transgene bearing mice were selected by Southern blot analysis of tail DNA $(10 \mu \mathrm{g})$ hybridised with the EF1 $\alpha$-EAT probe of the $6.7 \mathrm{~kb}$ PvuI-PvuI fragment. The founder mice obtained were assigned a number preceded with a letter E-for example, E3 or E12. Offspring were screened by detecting the 1097 bp human EAT fragment in the tail DNA by polymerase chain reaction (PCR) using a set of appropriate primers. The sequences of the primers used were as follows; sense, 5' CTGCATCGAACCATTAGCAG 3', antisense, 5' TACAACCAGTCTGCATACAG 3'.

$\mathrm{C} 3 \mathrm{H} / \mathrm{He}$ and $\mathrm{C} 57 \mathrm{BL} / 6$ mice, which are pigmented, were purchased from Clea Japan (Tokyo, Japan). All mice were maintained in our animal facility under specific pathogen-free conditions. The mice were housed under a controlled photoperiod (12 hours of light, 12 hours of darkness) and temperature $\left(22-25^{\circ} \mathrm{C}\right)$ and given water and chow ad labium in cages. The study was approved by the Keio University, School of Medicine, Laboratory Animal Care and Use Committee (No 001106).

\section{SOUTHERN BLOT ANALYSIS}

For Southern blot analysis, $5 \mu \mathrm{g}$ of total genomic DNA was digested to completion with EcoRI, separated by $0.8 \%$ agarose gel electrophoresis, and transferred to Hybond $\mathrm{N}+$ filters (Amersham, UK) in $1.5 \mathrm{M} \mathrm{NaCl} / 0.25 \mathrm{~N}$ $\mathrm{NaOH}$ (Fig 1A). The membranes were prehybridised at $65^{\circ} \mathrm{C}$ for 3 hours in $5 \times \operatorname{SSPE}(1 \times$ $\mathrm{SSPE}=0.15 \mathrm{M} \mathrm{NaCl}, 1 \mathrm{mM}$ EDTA and 0.01 $M$ sodium phosphate buffer), $5 \times$ Denhardt's solution, $1 \% \mathrm{SDS}$, and $10 \mu \mathrm{g}$ of poly $\mathrm{A} / \mathrm{ml}$, and then hybridised with the BamHI fragment of human EAT cDNA $(2.4 \mathrm{~kb})$ labelled with $\left[\alpha-{ }^{32} \mathrm{P}\right]-\mathrm{dCTP}$ by the random primer method at $1-3 \times 10^{9} \mathrm{cpm} / \mu \mathrm{g}$ of specific activity. ${ }^{56}$ After overnight hybridisation, blots were washed twice with $1 \times \mathrm{SSPE}, 1 \% \mathrm{SDS}$ at room temperature, twice with $1 \times$ SSPE, $1 \%$ SDS at $65^{\circ} \mathrm{C}$, and twice with $0.1 \times \mathrm{SSPE}, 0.1 \% \mathrm{SDS}$ at $65^{\circ} \mathrm{C}$, and then exposed to $x$ ray film.

EXPRESSION OF HUMAN EAT IN TRANSGENIC MICE Expression of human EAT transgene in the mice was examined by reverse transcription and polymerase chain reaction (RT-PCR). Briefly, retina from the mice were snap frozen in liquid nitrogen and homogenised in a microcentrifuge tube. RNA was extracted from these samples by Isogen (Nippon Gene, Japan). To eliminate the possibility of genomic DNA contamination, the RNA samples were further treated with RNase-free DNase and RNase inhibitor at $37^{\circ} \mathrm{C}$ for 1 hour followed by ethanol precipitation with the use of $t R N A$ as a carrier. Complementary DNA was generated using a first strand cDNA synthesis kit (Pharmacia Biotech, Uppsala, Sweden) and used as a template for PCR. Approximately 1-5 $\mu \mathrm{g}$ of total RNA was transcribed. PCR was carried out in $100 \mu \mathrm{l}$ reactions containing $1-7$ $\mu \mathrm{l}$ cDNA template, $200 \mathrm{mM}$ deoxynucleotide triphosphates, $0.5 \mathrm{mM}$ of each oligonucleotide primer, and 2.5 units of Taq polymerase in 10 
mM TRIS $\mathrm{HCl}$ buffer, $\mathrm{pH}$ 8.8, containing 50 $\mathrm{mM} \mathrm{KCl}, 1.5 \mathrm{mM} \mathrm{MgCl}_{2}$. Oligonucleotide primers used for PCR were: 5'CTGCATCGAACCATTAGCAG (sense) and 5'-TACAACCAGTCTGCATACAG (antisense). They were used to amplify a $1097 \mathrm{bp}$ fragment of human EAT cDNA without detecting the endogenous murine EAT gene. The PCR reaction was performed for 35 cycles with the following parameters: denaturing at $95^{\circ} \mathrm{C}$ for 1 minute, annealing at $55^{\circ} \mathrm{C}$ for 1 minute, and elongation at $72^{\circ} \mathrm{C}$ for 90 seconds. The amplified PCR products were electrophoresed on $0.7 \%$ agarose gels and either detected by ultraviolet illumination of ethidium bromide stained gels or transferred to filter and hybridised with ${ }^{32} \mathrm{P}$ labelled EAT cDNA as a probe.

Two lines (E13 and E12) of EAT transgenic mice incorporating the EF- $1 \alpha$ promoter were utilised. Expression of human EAT was

A

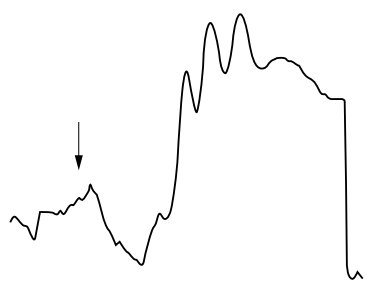

Score 2

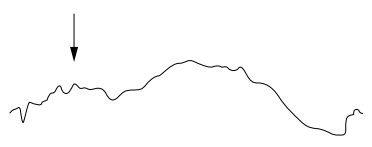

Score 1

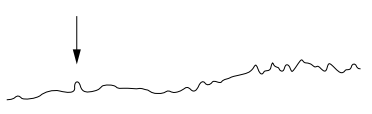

Score 0

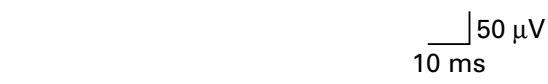

C

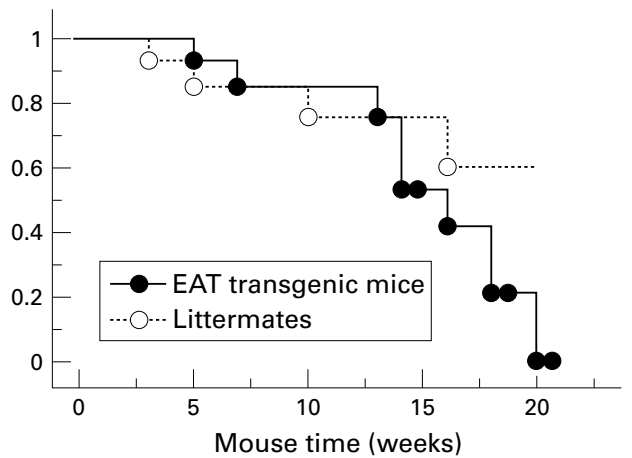

detected by RT-PCR in transgenic mice. Northern blot analysis of various tissues was initially carried out on both lines of transgenic mice to detect human EAT mRNA; however, no signals could be detected. Western blots using an EAT specific monoclonal antibody and a polyclonal antibody were likewise carried out on both lines to detect expression of human EAT protein; however, detectable levels of human EAT could not be observed. In vitro, cells transfected with the same transgene constructs have previously been shown to express the EAT protein by western blot analysis, ${ }^{57}$ confirming the integrity of these constructs. Expression of the EAT gene in various organs, as examined by RT-PCR (Fig 1C) revealed ubiquitous expression of EAT in transgenic mice. Strong expression of the transgene was noted in the retina. We concluded that the use of the EF-1 $\alpha$ promoter

B

Transgenic mice
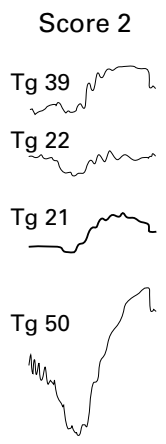

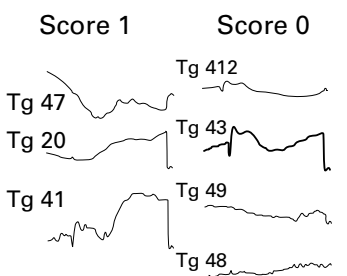

Tg 19

$\operatorname{Tg} 40$

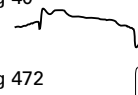

$10 \stackrel{\lrcorner \mathrm{ms}}{\lrcorner} \mu \mathrm{V}$
Littermates

Score 2

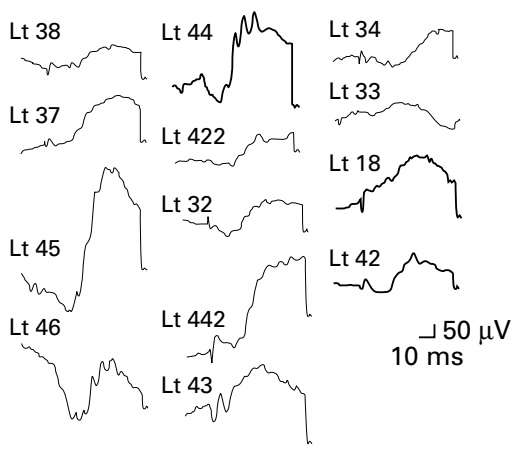
responses were scored by three observers unaware of the EAT genotype for the degree of potential rescue. The scores were based on scale 0 (severe damage with little or no rescue; almost non-recordable), 1 (little damage; a-wave and b-wave seen without oscillatory potentials), and 2 (no damage; $a, b$-wave amplitude and oscillatory potentials well preserved). Arrows indicate the point of light stimulation. (B) The ERG responses of each mouse. Mice were raised under cyclic room lighting until 35-91 days of age and then were placed in a temperature controlled environmental chamber illuminated continuously by 26 white fluorescent bulbs $(40 \mathrm{~W})$. The illumination in the chamber ranged from 400 to 500 lux. (C) Kaplan-Meier survival analysis of electrophysiological responses after constant light stimulation in EAT transgenic mice (solid circle) and littermates (open circle). Criteria for success and failure are described in the Materials and methods section. The estimated incidence of electrophysiological retinal damage was 0.0199/mouse/week in littermates, and 0.0495/mouse/week in EAT transgenic mice. 
resulted in expression of EAT transgene at levels detectable by RT-PCR.

INDUCTION OF LIGHT DAMAGE

As described by Lavail et al, mice were raised under cyclic room lighting until 5-13 weeks of age and then were placed in a temperature controlled environmental chamber illuminated continuously by 26 white fluorescent bulbs ( 40 W). Light intensity in the cages ranged from 400 to 500 lux. Groups of animals were examined by electroretinogram (ERG) testing after $3,5,7,9,10,13,14,16,18$, or 20 weeks in constant lighting, and then killed and tissues were taken for histology. The number of mice examined in each group was as follows: non-transgenic (littermate) at 3 weeks, $\mathrm{n}=1$; at 5 weeks, $\mathrm{n}=1$; at 7 weeks, $\mathrm{n}=1$; at 9 weeks, $\mathrm{n}=1$; at 10 weeks, $\mathrm{n}=1$; at 13 weeks, $\mathrm{n}=2$; at 14 weeks, $\mathrm{n}=1$; at 16 weeks, $\mathrm{n}=1$; at 18 weeks, $\mathrm{n}=2$; at 20 weeks, $\mathrm{n}=2$; and EAT transgenic at 3 weeks, $\mathrm{n}=1$; at 5 weeks, $\mathrm{n}=1$; at 7 weeks, $\mathrm{n}=1$; at 9 weeks, $\mathrm{n}=1$; at 10 weeks, $\mathrm{n}=1$; at 13 weeks, $\mathrm{n}=2$; at 14 weeks, $\mathrm{n}$

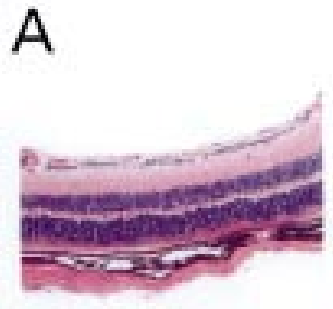

Score 3

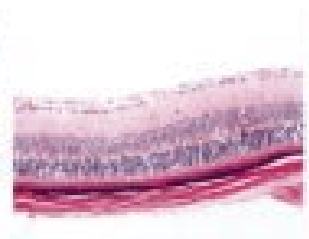

Score 2

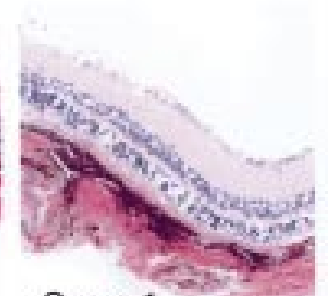

Score 1

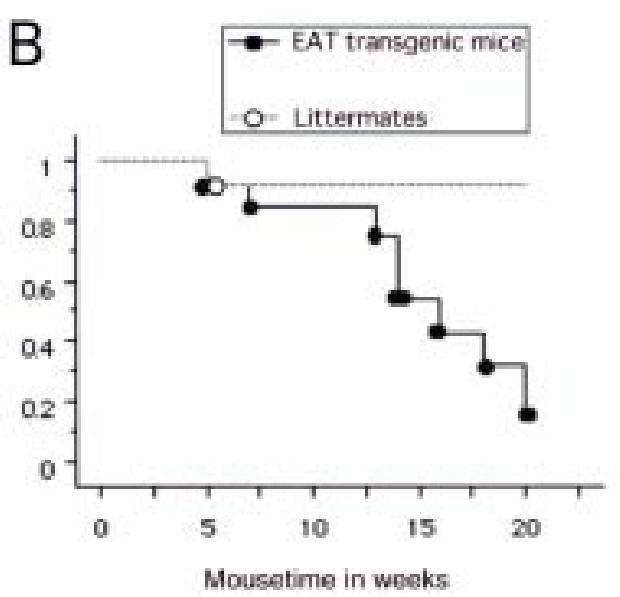

Figure 3 Light micrographs of mouse retinas taken from the posterior to equatorial region in the superior hemisphere of the eye. (A) Histological sections cut along the vertical meridian were scored by three observers for the degree of potential rescue, since the region is most sensitive to the damaging effects of constant light. The scores were: score 1 (the outer nuclear layer (ONL) has been reduced to about 3-5 rows of nuclei; disorganised inner segment (IS) and outer segment (OS) are still present), score 2 (photoreceptor IS and some disorganised OS are still present; the ONL still consists of approximately 6-8 rows of nuclei) and score 3 (almost normal structure with 9-10 rows of photoreceptor nuclei comprising the ONL). (B) Kaplan-Meier survival analysis of histopathological findings of the retina after constant light stimulation in the EAT transgenic mice (solid circle) and littermate (open circle). Criteria for success and failure are described in the Materials and methods section. The estimated incidence of histopathological retinal damage was 0.0042 /mouse/week in the littermates and 0.0419/mouselweek in the EAT transgenic mice.
$=2$; at 16 weeks, $\mathrm{n}=1$; at 18 weeks, $\mathrm{n}=2$; at 20 weeks, $\mathrm{n}=2$.

ELECTROPHYSIOLOGICAL STUDY

Mice were dark adapted for 12 hours before ERG testing as described. Anaesthesia was performed with inhalation of diethyl ether, and the anaesthetised animal was placed on a heating pad $\left(37^{\circ} \mathrm{C}\right)$. Pupils were dilated by $0.5 \%$ tropicamide. A corneal electrode, which was made from gold, instead of an intravitreous electrode, was used for recording. The ground electrodes were attached subcutaneously in the neck. A 26 gauge needle was placed subcutaneously in the head as a reference electrode. All manipulations were performed under very dim red light. Full field ERGs were elicited with 10 $\mu$ s flashes of xenon light $(20 \mathrm{~J})$ from a Ganzfeld dome on a steady background of $0 \mathrm{~cd} / \mathrm{m}^{2}$. Responses were differentially amplified at a gain of 10 000. Analysis time was $100 \mathrm{~ms}$. Single flash response was recorded. Four or eight flash responses were averaged if it was noisy. Flashes were presented at a rate of about 0.3 $\mathrm{Hz}$ manually. The recording band pass was 0.5-100 Hz. The ERG measurements were all made by the investigators blinded to the genotypes of the mice.

The ERG responses were scored by three observers masked with respect to the EAT genotype for the degree of potential rescue. The scores were defined as follows (Fig 2A): score 0 , severe damage with little or no rescue, almost non-recordable; score 1 , little damage, a and b-waves observed without oscillatory potentials; score 2, no damage, a, b-wave amplitude and oscillatory potentials well preserved.

Criteria for success were defined as good preservation of the oscillatory potentials-that is, scores of 0 or 1 were considered failure. Data were analysed statistically using KaplanMeier survival analysis with Mantel-Cox log rank test for estimation of success.

HISTOPATHOLOGICAL STUDY

After ERG recordings following a rigid proto$\mathrm{col}$, the anaesthetised animals were killed by cervical dislocation, and the eyes were processed for histology. After fixation for 1-2 days, the posterior segment containing the retina could be sectioned along the vertical meridian. Sections $(6 \mu \mathrm{m}$ thick) were processed and stained with haematoxylin and eosin.

Histological sections cut along the vertical meridian were scored by three observers for the degree of potential rescue. The scores were defined as follows (Fig 3A): score 0, severe damage with little or no rescue, all photoreceptor inner segment (IS) and outer segment (OS) missing, and the outer nuclear layer (ONL) reduced to less than a single or two rows of photoreceptor nuclei; score 1 , moderate damage, the ONL has been reduced to about 3-5 rows of nuclei; disorganised IS and OS are still present; score 2, little damage, photoreceptor IS and some disorganised OS are still present, the ONL still consists of approximately 6-8 rows of nuclei; and score 3, no damage, almost normal structure remained with 9-10 rows of 
photoreceptor nuclei comprising the ONL. The scores were done with the observers unaware of the EAT genotype and were based on ONL thickness in different regions of the eye as well as PR inner and outer segment length and integrity.

Criteria for success were defined as at least 3-5 rows of nuclei in ONL, where a score of 0 or 1 was considered failure. Data were analysed statistically using Kaplan-Meier survival analysis with Mantel-Cox log rank test for estimation of success. Statistical significance was set at 0.05 .

\section{Results}

We used ERG to estimate retinal function in mice carrying an EAT transgene under the $\mathrm{EF}-1 \alpha$ promoter. Light damage was induced in mice by constant illumination. EAT transgenic mice $(n=14)$ and control littermates $(n=13)$ were examined by ERG testing at various time points to 20 weeks of constant lighting stimulation. The ERG response score is shown in Table 1A. The mean scores (SD) of ERG dysfunction were significantly lower $(p<0.01)$ in the EAT transgenic mice $(0.79(0.89))$ than the littermates $(1.69(0.48))$. In addition, Kaplan-Meier curves showed a greater decline in electrophysiological response due to constant light in EAT transgenic mice than in littermates (Fig 2C). The estimated incidence of electrophysiological retinal damage was 0.0199/mouse/week (95\% CI 0.0035-0.0364) in the littermate and $0.0495 /$ mouse/week in the EAT transgenic mice $(95 \%$ CI $0.0347-$ 0.0500). The ERG responses of the retina deteriorated more markedly in the transgenic mice than in the littermates $(p=0.1156$, Kaplan-Meier survival analysis with MantelCox log rank test), suggesting that PR apoptosis under the constant light stimulation is likely to be accelerated by EAT (Fig 2B, C).

To determine whether this retinal dysfunction is caused by cell death or degeneration, we examined all retinas histopathologically. The results clearly showed that the electrophysiological disturbance was caused by loss of retinal cells. Histopathology scores are shown in Table 1B. There was a trend towards lower

Table 1 The ERG responses and histopathological findings of mice retina exposed to constant light stimulation

\begin{tabular}{|c|c|c|c|c|c|c|}
\hline \multirow[b]{2}{*}{$A$} & \multirow[b]{2}{*}{ Genotype } & \multicolumn{3}{|c|}{ Score } & \multirow[b]{2}{*}{ Total } & \\
\hline & & 0 & 1 & 2 & & \\
\hline & Transgenic & 7 & 3 & 4 & 14 & \\
\hline & Littermate & 0 & 4 & 9 & 13 & \\
\hline & & & & & & \\
\hline \multirow[t]{3}{*}{$B$} & Genotype & 0 & 1 & 2 & 3 & Total \\
\hline & Transgenic & 4 & 4 & 2 & 4 & 14 \\
\hline & Littermate & 0 & 1 & 7 & 5 & 13 \\
\hline
\end{tabular}

The ERG responses and histopathological findings were scored by three observers blinded to the EAT genotype for the degree of potential rescue. Definition of the scores are described in the Materials and methods section. (A) The mean score (SD) of the ERG response of EAT transgenic mice $(0.79(0.89))$ was significantly lower than that of the littermates $(1.69(0.48), \mathrm{p}=$ $0.0074)$. (B) The mean scores (SD) of the histopathological findings of the littermates $(2.31(0.63))$ versus EAT transgenic mice $(1.43(1.22))$ were not significantly different $(p=0.065)$. mean scores (SD) of histopathological change in the EAT transgenic mice $(1.43(1.22))$ than in littermates $(2.31(0.63))(p=0.065)$. The estimated incidence of histopathological retinal damage was $0.0042 /$ mouse/week in littermates (95\% CI 0-0.0120) and 0.0419/mouse/week in the EAT transgenic mice (95\% CI $0.0286-$ 0.0500). Retinal PR cells were significantly more impaired by constant light in the EAT transgenic mice than the littermate (Fig 3B, p $=0.0241$, Kaplan-Meier survival analysis with Mantel-Cox log rank test), implying that dysfunction detected by ERG is attributable to retinal cell death.

\section{Discussion}

Light induced apoptosis of retinal PRs has been well characterised, but the receptor mediating light damage has not yet been identified. ${ }^{43}$ Candidate molecules include prostaglandin synthase, ${ }^{58}$ cytochrome oxidase, ${ }^{59}$ rhodopsin, ${ }^{60}$ and opsins of the cones and the retinal pigment epithelium. ${ }^{61} \mathrm{c}$-fos, a transcription factor and a component of AP-1, has been reported to be essential for a specific premitochondrial "private apoptotic pathway" induced by light. ${ }^{62}$ In the present study, we have shown that retinal cell death by light was accelerated by EAT, a bcl-2 related gene, using EAT transgenic mice.

The proto-oncogene bcl-2 and its family, which are known to be potent regulators of apoptosis, have attracted great attention in light induced apoptosis (Fig 4). However, little remains known about their role. Chen et al reported that bcl- 2 overexpression reduces PRs apoptosis against sustained illumination. ${ }^{52}$ However, Joseph and $\mathrm{Li}$ reported that the outer layer thickness in bcl-2 or bcl-xL transgenic retinas was not significantly different from non-transgenic ones after exposure to excessive light stimulation. ${ }^{54}$ This is explained by the presence of multiple pathways of cell death in PRs that bypass regulation by bcl-2 family proteins.

Similar to bcl-2, EAT has been shown to inhibit apoptosis in vitro and in vivo. ${ }^{57} 63$ The ratio of anti-apoptotic (death antagonists) to pro-apoptotic bcl-2 related molecules (death agonists) is known to determine whether a cell will undergo apoptosis. This death-life balance is regulated partly by competitive dimerisation between pairs of antagonists and agonists ${ }^{2}$ (Fig 4). Similar to bcl-2, EAT may heterodimerise with Bax through $\mathrm{BH} 1$ and $\mathrm{BH} 2$ domains to repress apoptosis. ${ }^{186566}$ The interactions of EAT with Bax are more physiologically relevant in cells that fail to express bcl-2, as the bax gene is more widely expressed than bcl- $2 .{ }^{67}$ The current study is, to our knowledge, the first report to investigate the role of EAT in regulation of retinal $\mathrm{PR}$ cell death. The estimated incidence of electrophysiological and morphological retinal damage was increased by EAT.

There were five mice ( $\operatorname{Tg} 41, \operatorname{Tg} 472, \mathrm{Lt} 34$, Lt 18, and Lt 42) defined as "failure" in the electrophysiological study but as "success" in the histopathological findings. There was, however, no mouse defined as "success" in the electrophysiological study and as "failure" in 


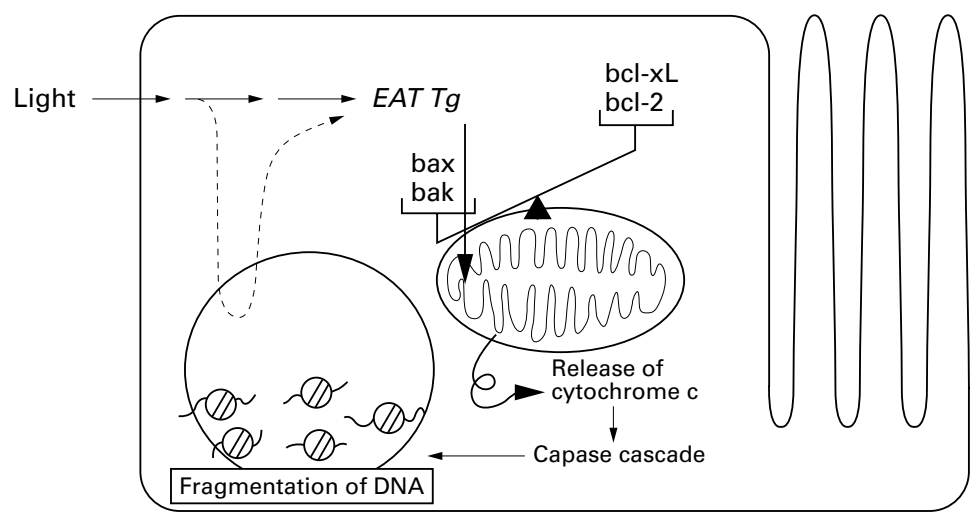

Figure 4 Schematic model of the mechanism of EAT transgene incorporation in promoting light induced apoptosis in the retina. Light triggers a signal cascade mechanism which initiates the apoptotic signal through activation of the $\mathcal{F N K}(S A P K)$ pathways and/or c-fos $(A P-1)$ transcriptional pathways. EAT and other $B c l-2$ related proteins act at the outer membrane of the mitochondria ${ }^{76}$ where the heterodimeric balance of bcl-2 related genes regulates the final execution stages of the apoptotic cascade. Bcl-2 related genes regulate mitochondrial membrane function; a loss in mitochondrial transmembrane potential leads to the release of AIF and cytochrome $c$. These factors then trigger apoptosis in which the caspase activated cascade leads to the activation of endonucleases resulting in DNA fragmentation. We hypothesise that incorporation of the EAT transgene shifts the balance of bcl-2 related heterodimeric molecules in the direction of promoting apoptotic effector signals. EAT promotes light induced apoptosis in retina by the above mechanism.

the histopathological findings. These results indicate that the electrophysiological response was more sensitive than histopathology for the evaluation of retinal cell apoptosis in the present study. The functional consequences of this degeneration seem to have a more rapid course of deterioration than do the histopathological ones. This is consistent with a previous report showing the retardation of PR degeneration in $P d e^{\mathrm{gtm} 1} / P d e g^{\mathrm{tm} 1}$ mice by the bcl-2 transgene, ${ }^{68}$ in which although both cell types were protected from cell death on microscopic examination, only the cone cells were functional, and not the rod cells, in signal transduction in ERG analysis.

There are two possible roles of EAT in cells exposed to cytotoxic agents. ${ }^{20}$ One possibility is that the rapid increase in EAT might provide an initial viability enhancing or death delaying response. In such cases, EAT might serve an anti-apoptotic function and might allow cells a margin of time to respond to the cytotoxic stimulus (for example, time to decide either to undergo apoptosis or to initiate further measures to prevent cell death). The other possibility is that EAT might have an as yet unproved dual role in the control of cell viability (as is seen with bax and bcl-xL, another member of the bcl-2 family $)^{69} 70$ and might in some way contribute to the death that follows increased EAT expression. In the current study, the observation that light induced apoptosis was accelerated in transgenic retina overexpressing EAT supports the latter hypothesis that anti-apoptotic $\mathrm{Bcl}-2$ and $\mathrm{Bcl}-\mathrm{xL}$ can convert into pro-apoptotic proteins. ${ }^{71}{ }^{72}$ Structural data indicate that the cleavage of $\mathrm{Bid}$, a $\mathrm{Bcl}-2$ related protein, by caspase- 8 induces a conformational change that may facilitate exposure of its $\mathrm{BH} 3$ domain. ${ }^{73}$ The $\mathrm{BH} 3$ domain may be involved in triggering death, and is conserved in Bax, EAT, Bcl-2, and BclxL. ${ }^{75}$ Perhaps like Bcl-2, EAT functions as an anti-apoptotic protein that can be converted into a pro-apoptotic protein by alternative splicing, phosphorylation, proteolytic cleavage, or relocalisation. The potential role of these factors in the chain of events leading to PRs cell death in the retina remains to be investigated. Elucidation of the apoptotic pathway in EAT transgenic mice may lead to identification of other factors that interfere with cell death and of molecular therapeutic strategies that might prevent retinal degeneration.

The first two authors contributed equally to this work

We are grateful to K Kita, J Ozawa, H Suzuki, S Kusakari, H Abe, Y Hashimoto, and T Honda for their technical assistance. This work was supported in part by a grant from the ministry of education, science and culture to JH and AU, by Keio Univereducation, science and culture to $\mathrm{JH}$ and AU, by Keio Univer-
sity special grant in aid for innovative collaborative research sity special grant in aid for innovative collaborative research project to $\mathrm{JH}$ and $\mathrm{AU}$, by Keio Gijuku Fukuzawa memorial University to HO, and by a national grant in aid for the establishment of a high tech research centre at private universities.

1 Kozopas KM, Yang T, Buchan HL, et al. MCL1, a gene expressed in programmed myeloid cell differentiation, has sequence similarity to BCL2. Proc Natl Acad Sci USA 1993;90:3516-20.

2 Kroemer G. The proto-oncogene Bcl-2 and its role in regulating apoptosis. Nat Med 1997;3, 614-20.

3 Revilla Y, Cebrian A, Baixeras E, et al. Inhibition of apoptosis by the African swine fever virus Bcl-2 homologue: role of the BH1 domain. Virology 1997;228:400-4.

4 Umezawa A, Maruyama $\mathrm{T}$, Inazawa $\mathrm{J}$, et al. Induction of mcl1/EAT, Bcl-2 related gene, by retinoic acid or heat shock in the human embryonal carcinoma cells, NCR-G3. Cell Struct Funct 1996;21:143-50.

5 Okita H, Umezawa A, Suzuki A, et al. Up-regulated expression of murine Mcl1/EAT, a bcl-2 related gene, in the early stage of differentiation of murine embryonal carcinoma stage of differentiation of murine embryonal carcinoma 1398:335-41.

6 1398:335-41. death. F Cell Biol 1994;124:1-6.

7 Reed JC. Mechanisms of Bcl-2 family protein function and dysfunction in health and disease. Behring Inst Mitt 1996;97:72-100.

8 Reed JC. Balancing cell life and death: bax, apoptosis, and breast cancer. $\mathcal{F}$ Clin Invest 1996;97:2403-4.

9 Boise LH, Gonzalez-Garcia M, Postema CE, et al. bcl-x, a bcl-2-related gene that functions as a dominant regulator of apoptotic cell death. Cell 1993;74:597-608.

10 Boyd JM, Gallo GJ, Elangovan B, et al. Bik, a novel death-inducing protein shares a distinct sequence motif with Bcl-2 family proteins and interacts with viral and cellular survival-promoting proteins. Oncogene 1995;11:19218.

11 Chittenden T, Harrington EA, O'Connor R, et al. Induction of apoptosis by the $\mathrm{Bcl}-2$ homologue Bak. Nature of apoptosis by

12 D'Sa-Eipper C, Subramanian T, Chinnadurai G. bfl-1, a bcl-2 homologue, suppresses p53-induced apoptosis and exhibits potent cooperative transforming activity. Cancer Res 1996;56:3879-82

13 Gibson L, Holmgreen SP, Huang DC, et al. Bcl-w, a novel member of the bcl-2 family, promotes cell survival. Oncogene 1996;13:665-75.

14 Inohara N, Ding L, Chen S, et al. Harakiri, a novel regulator of cell death, encodes a protein that activates apoptosis and interacts selectively with survival-promoting proteins Bcl-2 and Bcl-X(L). Embo f 1997; 16:1686-94.

15 Lin EY, Orlofsky A, Wang HG, et al. A1, a Bcl-2 family member, prolongs cell survival and permits myeloid differentiation. Blood 1996;87:983-92.

16 Thompson CB. Apoptosis in the pathogenesis and treatment of disease. Science 1995;267:1456-62.

17 Yang E, Korsmeyer SJ. Molecular thanatopsis: a discourse on the BCL2 family and cell death. Blood 1996;88:386401 .

18 Yang E, Zha J, Jockel J, et al. Bad, a heterodimeric partner for Bcl-XL and Bcl-2, displaces Bax and promotes cell death. Cell 1995;80:285-91.

19 Moulding DA, Giles RV, Spiller DG, et al. Apoptosis is rapdly triggered by antisense depletion of MCL-1 in differentiating U937 cells. Blood 2000;96:1756-63.

20 Yang T, Buchan HL, Townsend KJ, et al. MCL-1, a member of the BCL-2 family, is induced rapidly in response to signals for cell differentiation or death, but not to signals for cell proliferation. F Cell Physiol 1996;166:523-36.

21 Matsushita K, Umezawa A, Iwanaga S, et al. The EAT/mcl-1 gene, an inhibitor of apoptosis, is up-regulated in the early stage of acute myocardial infarction. Biochim Biophys Acta 1999;1472:471-8.

22 Wakabayashi $\mathrm{K}$, Saito $\mathrm{H}$, Ebinuma $\mathrm{H}$, et al. Bcl-2 related proteins are dramatically induced at the early stage of differentiation in human liver cancer cells by a histone deacetylase inhibitor projecting an anti-apoptotic role during this period. Oncol Rep 2000;7:285-8.

23 Christy BA, Lau LF, Nathans D. A gene activated in mouse 3 T3 cells by serum growth factors encodes a protein with 
zinc finger sequences. Proc Natl Acad Sci USA 1988;85: $7857-61$

24 Lau LF, Nathans D. Expression of a set of growth-related immediate early genes in $\mathrm{BALB} / \mathrm{c} 3 \mathrm{~T} 3$ cells: coordinate regulation with c-fos or c-myc. Proc Natl Acad Sci USA 1987;84:1182-6.

25 Reed JC, Tsujimoto Y, Alpers JD, et al. Regulation of bcl-2 proto-oncogene expression during normal human lymphocyte proliferation. Science 1987;236:1295-9.

26 Ryder K, Nathans D. Induction of protooncogene c-jun by serum growth factors. Proc Natl Acad Sci USA 1988;85: 8464-7.

27 Akgul C, Turner PC, White MR, et al. Functional analysis of the human MCL-1 gene. Cell Mol Life Sci 2000;57:684-91.

28 Moulding DA, Quayle JA, Hart CA, et al. Mcl-1 expression in human neutrophils: regulation by cytokines and correlation with cell survival. Blood 1998;92:2495-502.

29 Yang T, Kozopas KM, Craig RW. The intracellular distribution and pattern of expression of Mcl-1 overlap with, but are not identical to, those of Bcl-2.f Cell Biol 1995;128: are not icen $1173-84$.

30 Sano M, Umezawa A, Suzuki A, et al. Involvement of EAT/ mcl-1, an anti-apoptotic bcl-2-related gene, in murine embryogenesis and human development. Exp Cell Res 2000;259:127-39.

31 Suzuki A, Umezawa A, Sano M, et al. Involvement of EAT mcl-1, a bcl-2 related gene, in the apoptotic mechanisms underlying human placental development and maintenance. Placenta 2000;21:177-83

32 McDonnell TJ, Deane N, Platt FM, et al. bcl-2immunoglobulin transgenic mice demonstrate extended $\mathrm{B}$ cell survival and follicular lymphoproliferation. Cell 1989; 57:79-88

33 Sentman CL, Shutter JR, Hockenbery D, et al. bcl-2 inhibits multiple forms of apoptosis but not negative selection in thymocytes. Cell 1991;67:879-88.

34 Siegel RM, Katsumata M, Miyashita T, et al. Inhibition of thymocyte apoptosis and negative antigenic selection in
bcl-2 transgenic mice. Proc Natl Acad Sci USA 1992;89: bcl-2 trans.

35 Strasser A, Harris AW, Cory S. bcl-2 transgene inhibits T cell death and perturbs thymic self- censorship. Cell 1991; 67:889-99.

36 Veis DJ, Sorenson CM, Shutter JR, et al. Bcl-2-deficient mice demonstrate fulminant lymphoid apoptosis, polycystic kidneys, and hypopigmented hair. Cell 1993;75:229 40.

37 Brady HJ, Salomons GS, Bobeldijk RC, et al. T cells from baxalpha transgenic mice show accelerated apoptosis in response to stimuli but do not show restored DNA
damage-induced cell death in the absence of p53. gene product in. Embo f 1996;15:1221-30.

38 Brady HJ, Gil-Gomez G, Kirberg J, et al. Bax alpha perturbs $\mathrm{T}$ cell development and affects cell cycle entry of $\mathrm{T}$ cells. Embo f 1996;15:6991-7001.

39 Knudson CM, Tung KS, Tourtellotte WG, et al. Baxdeficient mice with lymphoid hyperplasia and male germ deficient mice with lymphoid hyp
cell death. Science 1995;270:96-9.

40 Abler AS, Chang CJ, Ful J, et al. Photic injury triggers apoptosis of photoreceptor cells. Res Commun Mol Pathol 92:177-89.

41 Hafezi F, Marti A, Munz K, et al. Light-induced apoptosis: differential timing in the retina and pigment epithelium. Exp Eye Res 1997;64:963-70.

42 Portera-Cailliau C, Sung CH, Nathans J, et al. Apoptotic photoreceptor cell death in mouse models of retinitis pigmentosa. Proc Natl Acad Sci USA 1994;91:974-8.

43 Reme CE, Grimm C, Hafezi F, et al. Apoptotic cell death in retinal degenerations. Prog Retin Eye Res 1998;17:443-64.

44 Cruickshanks KJ, Klein R, Klein BE. Sunlight and age-related macular degeneration. The Beaver Dam Eye Study. Arch Ophthalmol 1993;111:514-8.

45 Simons K. Artificial light and early-life exposure in age-related macular degeneration and in cataractogenic phototoxicity [letter; comment]. Arch Ophthalmol 1993; 111:297-8

46 Cideciyan AV, Hood DC, Huang Y, et al. Disease sequence from mutant rhodopsin allele to rod and cone photorecepfrom mutant rhodopsin allele to rod and cone photoreceptor degener.

47 Flannery JG, Farber DB, Bird AC, et al. Degenerative changes in a retina affected with autosomal dominant retinitis pigmentosa. Invest Ophthalmol Vis Sci 1989;30: $191-211$

$48 \mathrm{Li}$ ZY, Jacobson SG, Milam AH. Autosomal dominant retinitis pigmentosa caused by the threonine-17methionine rhodopsin mutation: retinal histopathology and immunocytochemistry. Exp Eye Res 1994;58:397-408

$49 \mathrm{Li} \mathrm{ZY,} \mathrm{Milam} \mathrm{AH.} \mathrm{In:} \mathrm{Anderson} \mathrm{RE,} \mathrm{La} \mathrm{Vail} \mathrm{MM,}$ Hollyfield JG, eds. Degenerative disease of the retina. New York: Plenum, 1995:1-8.

50 LaVail MM, Gorrin GM, Yasumura D, et al. Increased susceptibility to constant light in $\mathrm{nr}$ and pcd mice with inherited retinal degenerations. Invest Ophthalmol Vis Sci 1999;40:1020-4
51 Reme CE, Weller M, Szczesny P, et al. Light-induced apoptosis in the rat retina in vivo. In: Anderson RE, La Vail MM, Hollyfield JG, eds. Degenerative disease of the retina. New York: Plenum, 1995:19-25.

52 Chen J, Flannery JG, LaVail MM, et al. bcl-2 overexpression reduces apoptotic photoreceptor cell death in three different retinal degenerations. Proc Natl Acad Sci USA 1996;93:7042-7.

53 Nir I, Kedzierski W, Chen J, et al. Expression of Bcl-2 protects against photoreceptor degeneration in retinal degeneration slow (rds) mice. $\mathcal{F}$ Neurosci 2000;20:2150-4.

54 Joseph RM, Li T. Overexpression of Bcl-2 or Bcl-XL transgenes and photoreceptor degeneration. Invest Ophthalmol Vis Sci 1996;37:2434-46.

55 Hanaoka K, Hayasaka M, Uetsuki T, et al. A stable cellular marker for the analysis of mouse chimeras: the bacterial chloramphenicol acetyltransferase gene driven by the human elongation factor 1 alpha promoter. Differentiation 1991;48:183-9.

56 Feinberg AP, Vogelstein B. A technique for radiolabeling DNA restriction endonuclease fragments to high specific activity. Anal Biochem 1983;132:6-13.

57 Ando T, Umezawa A, Suzuki A, et al. EAT/mcl-1, a member of the bcl-2 related genes, confers resistance to apoptosis induced by cis-diammine dichloroplatinum (II) via a p53independent pathway. Fpn f Cancer Res 1998;89:1326-33.

58 Hanna N, Peri KG, Abran D, et al. Light induces peroxidation in retina by activating prostaglandin $\mathrm{G} / \mathrm{H}$ synthase. Free Radic Biol Med 1997;23:885-97.

59 Chen E. Inhibition of cytochrome oxidase and blue-light damage in rat retina. Graefes Arch Clin Exp Ophthalmol 1993;231:416-23.

60 Williams TP and Howell WL. Action spectrum of retinal light-damage in albino rats. Invest Ophthalmol Vis Sci 1983; 24:285-7.

61 Hao W, Fong HK. Blue and ultraviolet light-absorbing opsin from the retinal pigment epithelium. Biochemistry 1996;35: 6251-6.

62 Wenzel A, Grimm C, Marti A, et al. c-fos controls the private pathway; of light-induced apoptosis of retinal photoreceptors. 7 Neurosci $2000 ; 20: 81-8$.

63 Reynolds JE, Yang T, Qian L, et al. Mcl-1, a member of the Bcl-2 family, delays apoptosis induced by c-Myc overexpression in Chinese hamster ovary cells. Cancer Res 1994;54:6348-52.

64 Zhou P, Qian L, Bieszczad CK, et al. Mcl-1 in transgenic mice promotes survival in a spectrum of hematopoietic cell types and immortalization in the myeloid lineage. Blood 1998;92:3226-39.

65 Sato T, Hanada M, Bodrug S, et al. Interactions among members of the Bcl-2 protein family analyzed with a yeast two-hybrid system. Proc Natl Acad Sci USA 1994;91:923842 .

66 Sedlak TW, Oltvai ZN, Yang E, et al. Multiple Bcl-2 family members demonstrate selective dimerizations with Bax. Proc Natl Acad Sci USA 1995;92:7834-8.

67 Krajewski S, Bodrug S, Krajewska M, et al. Immunohistochemical analysis of Mcl-1 protein in human tissues. Differential regulation of $\mathrm{Mcl}-1$ and $\mathrm{Bcl}-2$ protein production suggests a unique role for Mcl-1 in control of programmed cell death in vivo. Am f Pathol 1995;146: 1309-19.

68 Tsang SH, Chen J, Kjeldbye H, et al. Retarding photoreceptor degeneration in Pdegtm1/Pdegtml mice by an apoptosis suppressor gene. Invest Ophthalmol Vis Sci 1997;38:943-50.

69 Oltvai ZN, Milliman CL, Korsmeyer SJ. Bcl-2 heterodimerizes in vivo with a conserved homolog, Bax, that accelerates programmed cell death. Cell 1993;74:609-19.

70 Yin XM, Oltvai ZN, Korsmeyer SJ. BH1 and $\mathrm{BH} 2$ domains of $\mathrm{Bcl}-2$ are required for inhibition of apoptosis and heterodimerization with Bax. Nature 1994;369:321-3.

71 Cheng EH, Kirsch DG, Clem RJ, et al. Conversion of Bcl-2 to a Bax-like death effector by caspases. Science 1997;278: 1966-8.

72 Clem RJ, Cheng EH, Karp CL, et al. Modulation of cell death by Bcl-XL through caspase interaction. Proc Natl Acad Sci USA 1998;95:554-9.

73 McDonnell JM, Fushman D, Milliman CL, et al. Solution structure of the proapoptotic molecule BID: a structural basis for apoptotic agonists and antagonists. Cell 1999;96: 625-34.

74 Chou JJ, Li H, Salvesen GS, et al. Solution structure of BID, an intracellular amplifier of apoptotic signaling. Cell 1999; 96:615-24.

75 Gross A, McDonnell JM, Korsmeyer SJ. BCL-2 family members and the mitochondria in apoptosis. Genes Dev 1999;13:1899-911.

76 Akgul C, Moulding DA, White MR, et al. In vivo localisation and stability of human Mcl-1 using green fluorescent protein (GFP) fusion proteins. FEBS Lett 2000;478:72-6. 